It is elegantly produced and dwells in detail on institutional and community programmes for rehabilitation and leisure activities of the physically handicapped mentally ill, mentally retarded, the ageing, and for socially deviant and dependent young citizens.

Much of the programming seems designed to ameliorate the baleful effects of institutional care which is the lot of many in the groups described. The wealth and resources devoted to transport, equipment and organisation of some of the programmes may not be available in poorer countries where the handicapped and aged are more usually kept within their own homes.

Culturally many of the activities proposed would not transpose to this side of the Atlantic particularly well. For instance, many handicapped people in these isiands are happily engaged tending their garden or pets. In Ireland a popular diversion for groups of old people is to hire a bus and take them all to an attractive pub for a singsong. Wheelchair and Darby and Joan clubs are popular here and there is already much interest and support for sporting activities such as the Wheelchair Olympics.
Some of the sections such as recreation and alcohol rehabilitation are short and lack detailed suggestions that might be useful here.

Whereas this volume may have a place in a rehabilitation clinic or library for occupational therapists it would seem that its readership will remain limited.

\section{E. J. BARNES.}

\section{CORRECTION}

Carcinogenicity Testing: Principles and Problems. Eds. A. D. Dayan and R. W. Brimblecombe. 1978. London. MTP Press Ltd. Price £8.95.

It is regretted that portion of the second paragraph of the review by Dr. M. L. Conalty of the above book, which appeared on page 121 of our March issue, was omitted. This should read: "A well-balanced consideration of the biochemical aspects of carcinogenesis is provided by T. A. Connors. O. H. Iverson describes his short-term in vivo test based on the increased deposition of formazan in skin exposed to carcinogens".

\title{
CURT P. RICHTER PRIZE
}

in

\section{PSYCHONEUROENDOCRINOLOGY}

Through the generosity of the Irish Foundation for Human Development, an annual prize has been established for meritorious research in the area of psychoneuroendocrinology. The aim of this essay prize is to encourage younger scientists to contribute to this interdisciplinary field and the sum of $\$ 1,000$ will be awarded annually for the best manuscript or essay submitted by a scientist or physician under 35 years of age. The winning paper will be published in the journal, Psychoneuroendocrinology. Submissions should be made in writing to:

Dr. Fleur L. Strand, Secretary, International Society of Psychoneuroendocrinology, New York University, Washington Square, New York, New York 10003, U.S.A.

All submissions will be screened by a broad committee of established psychoneuroendocrinologists. 